\title{
JCIHE: Vol. 13 Issue 1, 2021
}

Introduction

\author{
Rosalind Latiner Raby \\ California State University, Northridge \\ Editor-In-Chief
}

Dear Readers -

I am pleased to share the Volume 13, Issue 1, 2021 of the Journal of Comparative and International Higher Education (JCIHE). JCIHE is an open access, independent, double-blinded peerreviewed international journal publishing original contributions to the field of comparative and international higher education. The JCIHE is the official journal of the Comparative and International Education Society (CIES) Higher Education Special Interest Group (HESIG). The mission of the journal is to serve as a place to share new thinking on analysis, theory, policy, and practice, and to encourage reflective and critical thinking on issues that influence comparative and international higher education. JCIHE showcases new and diverse international research that uses rigorous methodology that focuses on theory, policy, practice, critical analysis, and development analysis of issues that are influence higher education. JCIHE has as its core principles: a) comparative research; b) engagement with theory; and c) diverse voices in terms of authorship.

As JCIHE growths in breadth and depth, it is important to continually refine a structure that is useable for our readership. Widespread recognition of the importance of comparative and international higher educational themes is resulting in quality manuscripts from authors from around the world. Due to the increase in accepted articles, JCIHE has moved to a 5-issue format, starting with this issue. In

Received March 1, 2021; revised March 1 2021; accepted March 1, 2021; electronically published March 2, 2021

Journal of Comparative \& International Higher Education

March, 2021, Vol. 13, No. 1, pp. 1-6.

DOI: $10.32674 /$ jcihe.v13i1.3618

(C) 2021 Journal of Comparative \& International Higher Education. All rights reserved. 
addition, JCIHE has added book reviews that will be accepted on a rolling basis. The first book review is included in this issue. Finally, JCIHE will soon be adding author short-videos describing their research.

The Issue 1 for 2021 includes 9 articles and a Book Review that identify current issues of higher education in Africa; Bulgaria; China; Japan; Turkey; United States; Vietnam. There are two broad themes that are the focus of this issue:

\section{Student Learning Strategies}

Student learning strategies and pedagogy are explored in six articles. Yao, Bush, Collins, Tuliao, Briscoe, Lan, and Dang examine self-regulated learning of STEM undergraduates in a Vietnamese Transnational university. Futagami examines motivations of international students studying in Japan research-intensive universities and captures their attitudes towards choosing to stay in Japan. CayetanoPenman examines coping abilities and self-management strategies learned by international students in an EMPOWERMENT program offered in a U.S. university. Kilc. Karadağ, Kılıç, and Demirel examine strategies that international nursing student adopt during their nursing practice in the clinic at a university in Turkey. Célestine and Mangue examines how two philosophies impact curriculum generation by comparing the Chinese policy of talent cultivation to the Western concept of academic

culture. Finally, Yamada explores the adoption of technological pedagogy in liberal arts curriculum as part of enabling Japan/s vision for Society 5.0.

\section{Institutional Focus}

A focus on institutional changes is explored in three articles. Bekelea and Thaddeus explores the strategic plan of 30 universities in Africa. Tananuraksakul examines the value and the use of English as a Global language in a Bulgarian higher education internationalization context. Finally, Gaudino examines School (K-12) District administrator perceptions and hiring practices of university students who are training to become teachers and who participated in education abroad programs. 
The JCIHE Volume 13, Issue 1, 2021 includes the following articles:

Christina W. Yao. University of South Carolina, United States, Trentee Bush, Northeast Community College, United States, Courtney Collins, University of Nebraska-Lincoln, United States, Minerva Tuliao, Texas Tech University, United States, Kaleb L. Briscoe, Mississippi State University, United States, and Ngoc Lan Thi Dang,Vietnamese-German University, Viet Nam. "Exploring STEM Undergraduate Self-Regulated Learning at a Vietnamese Transnational University". This article explores "New Model Universities" in Vietnam that partner with foreign institutions to offer self-regulated learning programs to supply the demand for quality STEM higher education. The article examples how the Vietnamese transnational experiences enable students engage in self-regulated learning and if such learning contributes to overall success.

Tsuneji Futagamia, Seigakuin University, Japan. "On motivations for mobility of international students studying in Japanese research-intensive universities". This article examines outcomes of the 2008 Japanese government 300,000 International Students Plan, the intent of which was to attract excellent international students and to encourage postgraduates to stay in Japan to assist the decreasing Japanese workforce. The article captures student voices as to why they choose to study in Japan, research capabilities, and their experiences while studying abroad.

Noparat Tananuraksakul, Rangsit University, Thailand. "Value and Use of English as a Global Language in a Bulgarian Higher Education Internationalization Context". This article examples the use of English as a global language (EGL) in Bulgarian higher education internationalization efforts. The focus is on the value and use of EGL as a de facto 'extraterritorial' lingua franca. The article also explores the linguistic, cultural, and 
psychological challenges that international students encounter as well as the determinants that impact their adjustment.

Teklu Abate Bekelea. American University in Cairo, Egypt and Denis Thaddeus Ofoyurub Gulu University, Uganda. "Emerging University-society Engagements in Africa: An Analysis of Strategic Plans". This article explores the strategic plans of 30 universities in Northern, Southern, Eastern, and Western Africa to assess external pressures from the need to demonstrate their relevance and significance to society poised to substantially reconceptualize their missions- education, research and community service. Using a S.W.O.T. analysis of Strengths, Weaknesses, Opportunities and Threats. Using this analysis, emerging engagement emphasis was analyzed in the strategic plans to target university-society engagements.

Aki Yamada, Tamagawa University, Japan. "Japanese Higher Education: The Need for STEAM in Society 5.0, an Era of Societal and Technological Fusion". This article explores how advanced technologies and service platforms integrate with and empower individuals in a human-based society with a focus on the potential role and benefits of incorporating liberal arts education into these technical studies, referred to as STEAM. The study shows how the humanities, social sciences, and arts can be used to enhance STEM education, and furthermore, how this STEAM approach to education is key to enabling Japan's vision for Society 5.0.

Ann C. Gaudino, Millersville University of Pennsylvania, United States. "School District Administrator Perceptions and Hiring Practices of Teachers Who Participated in International Student Teaching Placements". This article explores administrators' perspectives on hiring practices of teachers with internationalization experiences as being a benefit in terms of increased personal confidence, cultural awareness, ability to 
self-reflect on their professional practice and implement change, and ability to differentiate instruction for diverse learners. However, the study shows that these benefits did not help with the actual hiring as districts had no formal way of accounting for international student teaching experience any differently than student teaching experience in the United States.

Célestine Laure Djiraro Mangue, Higher Teachers' Training College, University of Maroua, Cameroon and Jean Gonondo, Higher Teachers' Training College, University of Maroua, Cameroon. "Academic Culture and Talent Cultivation: The Chinese Experience". This article examines the Western concept of 'academic culture' and the Chinese concept of 'talent cultivation'. The article examines the influence of 'academic culture' in the process of talent cultivation in the Chinese university context that is seen in internationalization practices and the innovation of scholars. The comparisons are then examined in relation to overall educational reforms.

Serap Palar Kilc, Inonu University, Turkey, Gülendam Karadağ, Dokuz Eylül University, Turkey, Nermin Kılıç, Firat University, Turkey, Cihat Demirel, Firat University, Turkey. “Difficulties and Expectations of Foreign Nursing Students in the Clinic". This article explores the difficulties and expectations of foreign nursing students during their nursing practice in the clinic at a university in Turkey. Socio-cultural and educational problems are affecting overall student success. The study shows that cultural differences did not seem to be the problem but applying treatments and applying care interventions were difficult based on their in-service training and former curricular experiences.

Joy Cayetano-Penman, Monash University, Australia, Gulzar Malik, La Trobe University, Australia, Kerry Hampton, Monash University, Australia, and Yaping Zhong, Monash University, Australia. "Conceptualising a Program Aimed at Empowering Beginning 
International Health Science Students for a Successful Transition to University". This article explores how a specific program in Australia, EMPOWERMENT, assisted beginning international students to expand coping abilities and self-management strategies. The goal was achieved in increasing resilience and improving skills to manage stress.

I want to thank several individuals who were instrumental in the publication of the 13(1), 2021. First, I want to give my profound thanks to the JCIHE editorial team: Associate Editor, Hayes Tang, CopyEditor Director, Nian Ruan and the Production Editor, Jie Liu. It is their dedication that helps keep the standards and integrity for the journal. I want to welcome Radomir Ray Mitic, New York University, United States who is the JCIHE Book Review Editor and Peter G. Ghazarian, Ashland University, United States who is the JCIHE Social Media Editor. I also want to thank Sasha Cui, the outgoing Social Media Editor for her years of service to the journal. Finally, I want to give special thanks to the JCIHE CopyEditors for this issue: Lul Admasachew; Nazgul Bayetova; Ryan Deuel; Michael Lanford; Rachel McGee; Sarah Schiffecker; and Nian Ruan; and Samantha Thompson.

Editor-in-Chief, Rosalind Latiner Raby 